\title{
Quality of Family Planning Care as Enabling Factor for Modern Contraceptive Use in Indonesia: Evidence from PMA2020 Survey
}

Nurjaeni Nurjaeni

Mahidol University https://orcid.org/0000-0001-8755-3457

Yothin Sawangdee ( $\nabla$ yothin.saw@mahidol.ac.th )

University of Mahidol

Umaporn Pattaravanich

Mahidol University

Charamporn Holumyong

Mahidol University

Aphichat Chamratrithirong

Mahidol University

Research

Keywords: quality, contraception, family planning, multilevel analysis, Indonesia

Posted Date: May 19th, 2021

DOI: https://doi.org/10.21203/rs.3.rs-516964/v1

License: (1) This work is licensed under a Creative Commons Attribution 4.0 International License.

Read Full License 


\section{Abstract}

\section{Background}

The utilization of modern family planning methods is a key pointer that mirrors universal access to reproductive health cares. Fulfilling unmet needs for modern contraceptives may decrease the level of maternal mortality by almost a third. This research employed the 2016 PMA2020 survey to assess multilevel variables related to modern family planning method use among women of reproductive age in Indonesia.

Method

Data from interviews of female and Service Delivery Point (SDP) of the 2016 Performance Monitoring and Accountability 2020 (PMA2020) survey were linked to generate a merged dataset comprising women's individual, cluster and SDP factors $(N=10,210)$. Multilevel analysis was done to assess the influence of contextual factors including a summary index of SDP quality FP care on woman's modern family planning practice. Adjusted odds ratios and $95 \% \mathrm{Cls}$ were analysed and interpreted.

Results

Modern contraceptive prevalence among women of childbearing age was $42.3 \%$ in 2016 . There was a considerable variation in the likelihood of modern method use across the 372 clusters/EAs. Age, education, marital status, parity, residency, region, woman's FP decision autonomy, cluster's average ideal number of children, percentage of females dissatisfied with FP, and percent of females visited by CHVs were significant factors for modern FP use after adjusting for multilevel characteristics. Quality of FP care was revealed to be a significant enabling factor for modern contraceptive use in Indonesia.

\section{Conclusions}

Modern contraceptive prevalence among females aged 15-49 years was relatively low in 2016 . The findings indicate that an advancement in modern method use can be gained by improving quality of family planning care. Likewise, an enhancement in women's FP decision autonomy and their level of education, decline in women's ideal number of children and diminution of the dissatisfaction with family planning are all major concerns to be addressed. Family planning policies must tackle adverse cultural norms and inequities in quality of family planning care and women's education that would produce welfares to women, children, and communities.

\section{Background}

Modern contraceptive utilization is a key pointer that mirrors universal access to reproductive health cares (1-3). Furthermore, the contraceptive prevalence rate (CPR) among women of reproductive ages is indicator 3.7.1 in the 3rd Sustainable Development Goals (SDGs) $(4,5)$. Raising modern family planning 
(FP) use is essential for accomplishing three of the SDG indicators, i.e. decreasing maternal deaths, enhancing child health, and lessening HIV/AIDS (6-9).

Indonesia has thrived major success in FP programs in last half centuries $(10,11)$. Nonetheless, modern contraceptive use in Indonesia has been an issue in last decade (12-14). Building and sustaining approaches of advancing the prevalent utilization of modern methods in Indonesia is a tough task for FP program planners and managers (12-14).

Furthermore, more than $10 \%$ of women of reproductive age in Indonesia have unmet needs for family planning (FP), mainly for modern contraceptives (15). Fulfilling unmet needs for modern contraceptives may decrease the level of maternal mortality up to one third $(16,17)$. Woman's characteristics including highest attended education and decisional autonomy are related to modern method usage (18-24). It is propositioned that some social contexts, including the cultural norms at the society wherein women live, could influence women's decision-making process in modern FP utilization as well $(25,26)$.

Even though drivers and barriers of modern FP practice in Indonesia have been examined in prior research, to authors' knowledge, no prior research have utilised nation-wide representative data and multilevel analysis to assess the net influence of social and family planning service factors on modern method utilization. This research employed nation-wide representative datasets from the 2016 Performance Monitoring and Accountability 2020 (PMA2020) Indonesia survey to assess the net effect of cluster and service delivery point (SDP) characteristics on women's likelihood to practice modern family planning methods. Social contexts were analysed at the cluster/community level, as were done in prior research $(27,28)$.

\section{Methods}

Data

Data used in this study were obtained from the 2016 PMA2020 Indonesia survey: This project was performed in 2016 in paralel with other international survey project of PMA2020 in other 10 countries, i.e. Ghana, Kenya, Uganda, Democratic Republic of Kongo, Ethiopia, Burkina Faso, Niger, Nigeria, Côte D'lvoire, and India (29). The 2016 PMA2020 Indonesia survey consists of women in reproductive age data from a national sample included 12,107 households, 10,565 females and 995 service delivery points (SDPs) in 372 clusters or enumeration areas (EAs) (30).

In this study, authors extracted family planning data from the female and SDP datasets across all 372 randomly chosen enumeration areas/clusters ( $N=10,210$ women). Authors then generated cluster or enumeration area (EA) data by agregating women's individual data for the purpose of multilevel analysis. Moreover, records from female and nearest SDP were merged using closest Global Positioning System points and 'EA ID' as the key variable to link both female and SDP datasets.

Variable Measurements 


\section{Outcome}

Modern method usage was defined based on female records whether she or her spouse was currently using a modern contraception, such as injectables, pills, implants, intra-uterine device (IUD), male or female sterilization, or condoms (female or male) at the time of interview. This dichotomous outcome variable was coded as 1 for "currently using a modern contraception" and 0 for "currently not using a modern contraception".

Level 1 explanatory variables

Independent factors added into level 1 of multilevel analysis comprised women's age (five years interval age groups), educational background (no school or primary school, junior or senior high school, and college/university), marital status (never married, married or living with spouse, and widow/divorced/ separated), number of living children ( 0 child, 1 child, 2 children, 3 children, and 4 or more children), socioeconomic status (lowest, low, middle, high, or highest), health insurance (no health insurance, non-free national health insurance, free national or district health insurance, and other health insurance), and family planning decision-making autonomy (low and high).

Level 2 explanatory variables

\section{Cluster/EAcharacteristics}

Cluster/EA characteristics inserted into level 2 of the multilevel analysis consisted residency (urban or rural) and region (Sumatera, Java and Bali, Nusa Tenggara, Kalimantan, Sulawesi, and Maluku and Papua). Other cluster/EA characteristics was generated by agregating individual data of women living in the same cluster/EA. Cluster/EA factors were developed for two aspects, i.e. 'cultural norms' and 'demand generating effort', that were commonly considered in literatures as part of the "social determinants" of modern family planning practice.

The 'cultural norms' aspect was constructed by 2 variables:

1. Percentage of cluster (EA) members who dissatisfied with FP.

A woman was classified as having dissatisfaction with FP if she cited her reason for not using a modern contraceptive was because of opposed by personal/spouse/religious view, or health concerns or fear of side effects.

2. Average ideal number of children of women in childbearing age who were living in the same cluster/EA.

Furthermore, the 'demand generating effort' aspect was as follows:

The percentage of cluster/EA members visited by village health worker or community health volunteer (CHV) who discussed FP in the past one year. 
SDP characteristics included in the level 2 of multilevel analysis were SDP classification (clinic or health center, delivery post or health post, private midwife or doctor, hospital, and others) and SDP quality of FP care $(\mathrm{Q} O C)$. The variable of SDP quality FP care $(\mathrm{Q} \circ \mathrm{C})$ was a synthesized index obtained from categorical PCA (principal component analysis). This composite variable was built using SPSS 20 by synthesizing fourteen quality components of family planning care as follows:

1. Available trained staff(s): whether trained staff(s) was available when SDP served contraceptive care to clients.

2. Days SDP offering contraceptive services: number of days in a week SDP provide contraceptive care.

3. Available access to water and electricity: whether SDP staff(s) had available access to water and electricity.

4. FP service charge: whether SDP charged clients for FP service.

5. Method choice: how many modern contraceptives offered by SDP.

6. FP method stock-out: Did SDP experience FP method stock-out in past 3 months.

7. FP kits and tools: number of available FP kits and tools in the family planning examination room.

8. FP Examination room: were contraception kept from rodents, water, and sun, and was there any dirts in FP examination room.

9. SDP supervision: has SDP been supervised in past 6 months.

10. SDP supporting CHVs: did SDP train or supply contraceptives to community health volunteers (CHVs).

11. Visual and auditory privacy: did SDP maintain auditory and visual privacy in FP examination room.

12. Evaluation of clients' feedbaks: did SDP evaluated clients' feedbacks.

13. Family planning service provision for adolescents: did SDP counsel//prescribe/offer contraceptives for adolescents.

14. Post-abortion care: did SDP provide post-abortion care.

Moreover, factor weights (composite quality scores) were then normalized and each SDP was attached with a quality index. This composite index of quality FP care was classified by its tertiles, denoting low, medium, or high quality family planning care.

Statistical analysis

This research performed multilevel analysis using STATA 14 by two-level mixed effect logistic regression model which was able to:

- Assessed the independent influences of cluster/EA and SDP factors on women's odds of using modern methods, and

- Addressed the cluster effects due to multistage cluster sampling design of PMA2020 survey. 
This research studied a binary dependent variable of modern FP practice. Authors performed these model building approaches to gain an unbias mixed effect model which predicts the odds of women of reproductive age in Indonesia to utilise modern FP supplies:

- First phase: A 'null model' without any independent variables was analysed to verify whether there was a significant variation across clusters/EAs regarding the odds of modern method usage. This empty model confirmed whether there was any significant random effect on multilevel model, by cheking whether the variance of multilevel model intercept was significant or not.

- Second phase: A full or comprehensive model with all explanatory variables (level 1 and level 2) was then built to assess the independent influence of cluster/EA and SDP factors, and to investigate whether there was any significant cross-level interaction between explanatory variables at both level.

\section{Results}

Modern contraceptive prevalence

Figure 1 and 2 display the modern contraceptive prevalence in 2016. The percentage of women of reproductive age using modern FP supplies in Indonesia was $42.33 \%$ and around $57.7 \%$ were contraceptive non-users and traditional method users (Figure 1). Figure 2 depicts that among modern FP users, around $53.33 \%$ were injectable method users, $20.99 \%$ were contraceptive pill users, $9.32 \%$ were using implants, $7.77 \%$ were using IUD, $6.15 \%$ were female sterilization users, $2.31 \%$ were condom users, and about $0.12 \%$ females reported that their spouse had been sterilized.

Female individual characteristics in 2016 PMA2020 Indonesia survey

Table 1 exhibits the characteristics of women of reproductive age in this study. Approximately $14.47 \%$ were aged 15-19 years, and more than one-quarter were aged over 40 years. Around $57.32 \%$ had attended high school and only $14.59 \%$ had attended academy/university. The percentage of females had 2 children was $26.75 \%$ and about $28.39 \%$ had no parity. Regarding marital status, roughly $71.87 \%$ of women of reproductive age were married or living with a spouse. Nearly $59.01 \%$ of women had a higher decisional autonomy in family planning and about $25.38 \%$ had a high socio-economic status, but more than $39 \%$ of women had no health insurance (see Table 1).

Clusters/EAs characteristics in 2016 PMA2020 Indonesia survey

Table 2 portrays the factual characteristics of the 372 clusters/EAs in the 2016 PMA2020 Indonesia survey. The cluster/EA average ideal number of children was 2.7 (SD 0.48). The mean proportion of women dissatisfied with modern contraception in cluster/EA was $15.05 \%$ (SD 12.02\%). The mean proportion of females in cluster/EA had been visited by CHV about Family Planning was $9.49 \%$ (SD $12.59 \%$ ). Regarding residency, approximately $55.22 \%$ of women lived in urban settings and majority of women (48.72\%) were living in Java-Bali region (see Table 2).

Table 1. Descriptive analysis of individual variables 


\begin{tabular}{|c|c|c|}
\hline Individual Factors & Number of women & Proportion \\
\hline \multicolumn{3}{|l|}{ Marital status } \\
\hline Never married & 2,433 & 0.238 \\
\hline Married or living with spouse & 7,338 & 0.719 \\
\hline Divorced/Separated/Widow & 439 & 0.043 \\
\hline \multicolumn{3}{|l|}{ Highest attended education } \\
\hline None / Primary School & 2,868 & 0.281 \\
\hline High School & 5,852 & 0.573 \\
\hline College/University & 1,490 & 0.146 \\
\hline \multicolumn{3}{|l|}{ Female's age } \\
\hline $15-19$ & 1,477 & 0.145 \\
\hline $20-24$ & 1,303 & 0.128 \\
\hline $25-29$ & 1,292 & 0.127 \\
\hline $30-34$ & 1,532 & 0.150 \\
\hline $35-39$ & 1,679 & 0.164 \\
\hline $40-44$ & 1,586 & 0.155 \\
\hline $45-49$ & 1,341 & 0.131 \\
\hline \multicolumn{3}{|l|}{ Socio-economic status } \\
\hline Lowest & 1,675 & 0.164 \\
\hline Low & 1,791 & 0.175 \\
\hline Middle & 1,873 & 0.183 \\
\hline High & 2,591 & 0.254 \\
\hline Highest & 2,280 & 0.223 \\
\hline \multicolumn{3}{|l|}{ Parity ${ }^{\mathbf{a}}$} \\
\hline 0 child & 2,896 & 0.284 \\
\hline 1 child & 1,823 & 0.179 \\
\hline 2 children & 2,728 & 0.268 \\
\hline 3 children & 1,581 & 0.155 \\
\hline 4 or more children & 1,171 & 0.115 \\
\hline
\end{tabular}




\begin{tabular}{|lll|}
\hline Health insurance & & \\
\hline No health insurance & 4,004 & 0.392 \\
\hline Free National/District Health Insurance & 2,165 & 0.212 \\
\hline Non-free National Health Insurance & 1,975 & 0.193 \\
\hline Other health insurance & 2,066 & 0.202 \\
\hline FP Decision-making Autonomyb & & \\
\hline Low (Decided by other/s) & 4,061 & 0.410 \\
\hline High (Decided by oneself) & 5,846 & 0.590 \\
\hline
\end{tabular}

a 11 missing values.

b 303 missing values.

Table 2. Descriptive analysis of cluster/EA and SDP variables 


\begin{tabular}{|c|c|c|}
\hline Contextual Factors & Number of women & Proportion \\
\hline \multicolumn{3}{|l|}{ Region } \\
\hline Sumatera & 1,870 & 0.183 \\
\hline Java and Bali & 4,974 & 0.487 \\
\hline Nusa Tenggara & 386 & 0.038 \\
\hline Kalimantan & 489 & 0.048 \\
\hline Sulawesi & 2,271 & 0.222 \\
\hline Maluku and Papua & 220 & 0.021 \\
\hline \multicolumn{3}{|l|}{ Residency } \\
\hline Rural & 4,572 & 0.448 \\
\hline Urban & 5,638 & 0.552 \\
\hline Proportion of females visited by CHV discussed FP in past 1 year & 9.49 (mean) & $12.59(\mathrm{SD})$ \\
\hline Percent of females dissatisfied with FP & 15.05 (mean) & $12.52(\mathrm{SD})$ \\
\hline Cluster/EA average ideal number of children & 2.66 (mean) & $0.48(S D)$ \\
\hline \multicolumn{3}{|l|}{ Quality of Care (QoC) ${ }^{c}$} \\
\hline Low & 2,733 & 0.284 \\
\hline Medium & 5,636 & 0.586 \\
\hline High & 1,243 & 0.129 \\
\hline \multicolumn{3}{|l|}{ SDP classification } \\
\hline Hospital & 249 & 0.024 \\
\hline Clinic/health center & 5,924 & 0.580 \\
\hline Delivery/health post & 1,923 & 0.188 \\
\hline Private Midwife/Doctor & 1,539 & 0.151 \\
\hline Other types & 575 & 0.056 \\
\hline
\end{tabular}

c 598 missing values.

Synthesized Index for Quality of Care (QoC) 
Table 3 disloses the result of categorical principal component analysis which found one single component that explaining the major variation in fourteen quality elements among 992 SDPs. The single component had acceptable eigenvalue and Cronbach's alpha (5.248 and 0.872 respectively). Support for CHVs and clients' visual and auditory privacy had the highest loadings (0.958 and 0.957 respectively). Post-abortion care (0.964), access to water and electricity (0.838), and number of FP methods offered by SDP (0.792) were also greatly loaded. Oppositely, FP service charge, number of days SDP served FP care, and FP service provision for adolescent were the lowest loading factors $(-0.247,-0.170$, and -0.085 in respective order). The quality scores then were normalized as shown in Figure 3.

\section{Table 3: Synthesized index of quality FP care of the nearest SDPs $(n=992)$}

\begin{tabular}{|ll|}
\hline Factors & Component Loadings \\
\hline 1. Available trained FP staff(s) & 0.667 \\
\hline 2. Number of FP kits and tools in examination room & 0.190 \\
\hline 3. Available access to water and electricity & 0.838 \\
\hline 4. FP examination room condition & 0.628 \\
\hline 5. Number of days in a week SDP served FP service & -0.170 \\
\hline 6. Number of methods offered by SDP & 0.792 \\
\hline 7. FP service charge & -0.247 \\
\hline 8. FP method stock out in past 3 months & 0.317 \\
\hline 9. SDP supervision in past 6 months & 0.169 \\
\hline 10. SDP supports for CHVs & 0.958 \\
\hline 11. Clients' opinions evaluation & 0.229 \\
\hline 12. Client's confidentiality in the examination room & 0.957 \\
\hline 13. Provision of post abortion care & 0.964 \\
\hline 14. Provision of FP service for adolescents & -0.085 \\
\hline Eigenvalue & $\mathbf{5 . 2 4 8}$ \\
\hline Cronbach's alpha & $\mathbf{0 . 8 7 2}$ \\
\hline
\end{tabular}

Multilevel Mixed-effect Logistic Regression Model

The multilevel analysis results presented in Table 4 signifies which individual, cluster/EA, and SDP factors had substantial influences on the odds of modern method utilization. Of the fourteen level 1 and level 2 variables, eleven had indicated a statistical relationship with modern family planning practice, i.e. female's age, high school education, number of living children, marital status, FP decision-making autonomy, free 
health insurance, residency and region, community average ideal number of children, proportion of cluster members dissatisfied with family planning, proportion of cluster members visited by CHV, and SDP quality of FP care (see Table 4). Nevertheless, there were 2 variables which had no significant relation to modern contraceptive use, i.e. socio-economic status and SDP classification.

Table 4 depicts the multilevel analysis findings which predict the women's odds to utilise modern FP methods. It is evident that the relation between SDP quality of care and woman's contraceptives usage was a positive association, where the odds of modern FP practice was greater among females living closest to SDP having high quality care (AOR=1.42, 95\% Cl: 1.11-1.82). Contrastly, residing in community with a higher average ideal number of children or a higher proportion of women dissatisfied with FP were significantly related to a lower odds of utilising a modern method (AOR=0.58, 95\% Cl: 0.49-0.68 and $\mathrm{AOR}=0.96,95 \% \mathrm{Cl}: 0.96-0.97$ respectively). Even so, a higher percentage of females visited by community health volunteer was statistically related to a higher likelihood of modern method use (AOR=1.01,95\% $\mathrm{Cl}$ : 1.00-1.01).

Table 4: Findings from the null model and the full model of multilevel mixed-effect logistic regression for modern FP method use among Indonesian females aged 15 to 49 years

\begin{tabular}{|lcrr|}
\hline Variables & NULL & \multicolumn{2}{c|}{ FULL MODEL } \\
& MODEL & AOR $^{\mathbf{d}}$ & $(95 \% \mathrm{Cl})$ \\
\hline
\end{tabular}




\begin{tabular}{|c|c|c|}
\hline \multicolumn{3}{|l|}{ Marital status } \\
\hline Never married & 1 & \\
\hline Married or living with spouse & 55.08 & $(21.07-143.95)^{\star \star \star}$ \\
\hline Divorced/Separated/Widow & 1.17 & $(0.40-3.41)$ \\
\hline \multicolumn{3}{|l|}{ Highest attended education } \\
\hline None / Primary School & 1 & \\
\hline High School & 1.13 & $(0.98-1.30)^{*}$ \\
\hline College/University & 0.95 & $(0.76-1.19)$ \\
\hline \multicolumn{3}{|l|}{ Female's age } \\
\hline $15-19$ & 1 & \\
\hline $20-24$ & 0.96 & $(0.55-1.64)$ \\
\hline $25-29$ & 0.46 & $(0.27-0.79)^{\star \star \star}$ \\
\hline $30-34$ & 0.32 & $(0.18-0.54)^{\star \star \star}$ \\
\hline $35-39$ & 0.27 & $(0.16-0.47)^{\star \star \star}$ \\
\hline $40-44$ & 0.20 & $(0.11-0.34)^{\star \star \star}$ \\
\hline $45-49$ & 0.09 & $(0.05-0.15)^{\star \star \star}$ \\
\hline \multicolumn{3}{|l|}{ Socio-economic status } \\
\hline Lowest & 1 & \\
\hline Low & 1.09 & $(0.89-1.33)$ \\
\hline Middle & 0.99 & $(0.81-1.22)$ \\
\hline High & 1.03 & $(0.84-1.28)$ \\
\hline Highest & 1.03 & $(0.82-1.30)$ \\
\hline \multicolumn{3}{|l|}{ Parity } \\
\hline 0 child & 1 & \\
\hline 1 child & 30.05 & $(17.88-50.49)^{\star \star \star}$ \\
\hline 2 children & 80.87 & $(47.54-137.58)^{\star \star \star}$ \\
\hline 3 children & 115.63 & $(67.16-199.09)^{\star \star \star}$ \\
\hline 4 or more children & 99.54 & $(57.15-173.39)^{\star \star \star}$ \\
\hline Health insurance & & \\
\hline
\end{tabular}




\begin{tabular}{|lll|}
\hline No health insurance & 1 & \\
\hline Free National/District Health Insurance & 1.15 & $(0.98-1.35)^{\star}$ \\
\hline Non-free National Health Insurance & 1.08 & $(0.91-1.28)$ \\
\hline Other health insurance & 1.11 & $(0.95-1.31)$ \\
\hline FP Decision-making Autonomy & & \\
\hline Low (Decided by other/s) & 1 & \\
\hline High (Decided by oneself) & 2.86 & $(2.49-3.29)^{\star \star \star}$ \\
\hline
\end{tabular}

d Adjusted to other covariates in the model.

1: Reference category; AOR: adjusted odds ratio; Cl: Confidence Interval.

$\star a=0.10 ; * \star a=0.05 ; * \star \star a=0.01$

Table 4: Findings from the null model and the full model of multilevel mixed-effect logistic regression for modern FP method use among Indonesian females aged 15 to 49 years (continued)

Characteristics

NULL MODEL

FULL MODEL

AOR $^{d} \quad(95 \% \mathrm{Cl})$ 


\section{Region}

Sumatera

1

Java and Bali

1.30

$(1.06-$

$1.60)^{\star \star}$

Nusa Tenggara

0.67

$(0.45-$ $1.00)^{*}$

Kalimantan

1.39

(0.96$2.01)^{*}$

Sulawesi

0.68

$(0.53-$ $0.87)^{\star \star \star}$

Maluku and Papua

1.12

(0.64 1.95)

\section{Residency}

Rural

1

Urban

0.71

$(0.60-$ $0.84)^{\star \star \star}$

Proportion of women visited by $\mathrm{CHV}$ discussed about 1.01

$(1.00-$ FP in past 1 year

Percent of females dissatisfied with FP

0.96 $1.01)^{\star \star}$ $(0.96-$ $0.97)^{\star \star \star}$

Cluster average ideal number of children

0.58

$(0.49-$ $0.68)^{\star \star \star}$

Quality of Care (QoC)

Low 1

Medium

1.03

$(0.87-$ 1.21)

High

1.42

$(1.11-$ $1.82)^{\star \star \star}$

SDP classification

Hospital

1

Clinic/health center

1.05

(0.64 -

1.74)

Delivery/health post

1.30

(0.77-

2.19)

Private Midwife/Doctor

1.22

$(0.72-$ 2.06)

Other types 


\section{Random Effect}

\begin{tabular}{llll|} 
random Intercept & $0.49(0.40-$ & 0.10 & $0.05-$ \\
random Slope of woman's autonomy & $0.61)^{\star \star \star}$ & & $0.19 \star \star \star$ \\
Lr test & & 0.27 & $0.48^{\star \star \star}$ \\
Wald Chi-Square & $\mathrm{X}^{2}=505.8, P<0.001$ & $\mathrm{X}^{2}=42.50$ & $\mathrm{P}<0.001$ \\
Model Fitness & & $\mathrm{X}^{2}=1277.2$ & $\mathrm{P}<0.001$ \\
\hline AIC & & & \\
BIC & 13,411 & 7725 & \\
Mean VIF & 13,425 & 8010 & \\
\hline
\end{tabular}

d Adjusted to other covariates in the model.

1: Reference category; AOR: adjusted odds ratio; Cl: Confidence Interval.

$\star a=0.10 ; * \star a=0.05 ; * \star \star a=0.01$

VIF = Variance Inflation Factors

AIC = Akaike information criterion .

$\mathrm{BIC}=$ Bayesian information criterion.

Moreover, Table 4 shows significant difference in women's odds of using modern method between high and low woman's FP autonomy (AOR=2.86, 95\% Cl: 2.49-3.29). In addition, women attended high shool had greater odds in modern contraceptive use than those with none/primary school (AOR=1.13, 95\% Cl: 0.98-1.30). Similarly, compared to women with no health insurance, women having a free national/district health insurance had a higher likelihood of using modern contraceptives ( $A O R=1.15,95 \%$ Cl: 0.98-1.35).

Table 4 also reveals that the variance for intercept of the null model was significant $(\sigma=0.49 ; 95 \% \mathrm{Cl}: 0.40$ $0.61 ; p<0.001)$ validating that the multilevel model intercepts was significantly random. In addition, the variance for the slope of variable FP decision-making autonomy in the full model was also significant $(\sigma=0.27 ; 95 \% \mathrm{Cl}: 0.15-0.48 ; p<0.001)$, it means that the relation between women's FP decision-making autonomy and modern contraceptive use varied across 372 cluster/EAs. Overall, the modern contraceptive use model resulted from multilevel logistic regression analysis had evidently random intercepts and random slopes for variable of FP decisional autonomy, indicating that the modern contraceptive use model significantly differed among all clusters/EAs. 


\section{Discussion}

The research findings revealed that the odds of women of childbearing age using modern contraception greatly varied across the 372 cluster/EAs. This study identified substantial relationship between quality of family planning care and modern contraceptive use. Particularly, SDP quality of care had a positive association with women's family planning practice, females lived closest to an SDP providing high quality of care had higher odds of using modern methods. This pattern are consistent with study findings from other research (31-33).

Our findings also found that the cluster average ideal number of children and percentage of cluster members dissatisfied with FP influenced the likelihood of individual woman to use a modern FP method. More or less, it indicates that social beliefs may impede the demand for family planning. It also reflects that cultural and traditional norms play an important role in modern contraceptive prevalence. Prior research suggested that prevailing community values may influence woman's decision in family planning practice at the individual level (25-28).

It was exciting to acknowledge that women living in rural areas had a higher likelihood in modern contraceptive use. It may be rationalised by the national FP programs in Indonesia targeting rural women (34). Therefore, it can be viewed as an achievement of national government intervention initiatives implemented at rural areas.

\section{STRENGTHS AND LIMITATIONS}

This study used the latest PMA2020 Indonesia survey datasets which were gathered between October 2016 and January 2017, thus the research findings are still relevant to be considered for current policy analysis. Moreover, the measurement and variables employed in this study are equivalent and compatible with those commonly used in global research. In addition, the multilevel analysis let us to identify the net effect for multidimensional variable of quality family planning care, and to earn better estimates by addressing cluster effects from multistage cluster sampling design.

Though, this study has several limitations. Firstly, the 2016 PMA2020 Indonesia survey data are crosssectional, hence, study results should be interpreted with caution due to inability to infer a causal-impact relation. Also, analysing secondary data constricted authors to include unavailable factors that may influence modern method use, such as client's satisfaction which is part of Donabedian quality framework (35). It is possible that female respondents were using or not using modern contraception due to other variables not available in the datasets. Thus, it may affect the significance of variance for the intercept of multilevel model, adjusted for other covariates in the study.

\section{Conclusions}

In summary, the modern contraceptive prevalence in Indonesia was relatively low in 2016 . The odds of women of reproductive age using modern family planning methods statistically differed across 372 
clusters/EAs. The findings indicate that an advancement in modern method use can be gained by improving quality of family planning care. Likewise, an enhancement in women's FP decision autonomy and their level of education, decline in women's ideal number of children and diminution of the dissatisfaction with family planning are all major concerns to be addressed. Family planning policies must tackle adverse cultural norms and inequities in quality of FP care and women's education that would produce welfares to women, children, and communities.

\section{Abbreviations}

SDG : Sustainable development Goals;

QoC : Quality of Family Planning Care;

AOR : Adjusted Odd Ratio;

Cl : Confidence Interval;

AIC : Akaike information criterion;

BIC : Bayesian information criterion;

VIF : Variance Inflation Factors;

PMA : Performance, Monitoring and Accountability;

FP: Family Planning;

EA : Enumeration Area;

SDP : Service Delivery Point;

GPS : Global Positioning System;

CHV : Community Health Volunteer;

\section{Declarations}

\section{Acknowledgements}

We are grateful to Center of Reproductive Health, Gajah Mada University for making the datasets available for this research.

\section{Authors' contributions}

YS, UP, $\mathrm{CH}$, and $\mathrm{AC}$ help NN conceptualized and designed the research; NN were responsible for data analysis, interpretation, and drafting the manuscript; YS, UP, $\mathrm{CH}$, and $\mathrm{AC}$ was responsible for critical 
revision of the manuscript. All authors read and approved the final draft.

\section{Funding}

The research was funded by the Indonesian National Population and Family Planning Board (NPFPB). However, NPFPB played no role in this research.

\section{Availability of data and materials}

To access the data used in this study, administrative permissions were required and obtained from The Center of Reproductive Health, University of Gajah Mada:

Office: C24 Mahoni Road, Jogjakarta, Indonesia, Postcode 55281

Email: pskespro.fkkmk@ugm.ac.id

\section{Ethics approval and consent to participate}

As the study entailed secondary analysis of existing data containing no personal identifying information, an exemption from ethical review requirements was granted by the the Institutional Ethical Review Board, Mahidol University, Thailand. Consent to participate was not an issue for the same reason.

\section{Consent for publiation}

Not applicable.

\section{Competing interest}

The authors have no conflict of interest to conduct this research.

\section{Author details}

${ }^{1}$ Institute of Population and Social Research, University of Mahidol, Thailand

${ }^{2}$ Indonesian National Population and Family Planning Board

\section{References}

1. United Nations Population Fund UNFPA. Universal Access to Reproductive Health: Progress and Challenges. UN Population Fund, U.N.F.P.A.; 2016. 2. United Nations Population Fund UNFPA. How universal is access to reproductive health? A review of evidence. New York; 2010. 3. United Nations Population Fund UNFPA. Universal Access to Reproductive Health Services: An Unfinished Business. Jakarta: UNFPA; 2012. Available from: https://indonesia.unfpa.org/sites/default/files/pubpdf/Booklet_Universal_Access_to_Reproductive_Health.pdf. 4. United Nations UN. Transforming our World: the 2030 Agenda for Sustainable Development. eSocialSciences; 2015. 5. United Nations UN. The 
Sustainable Development Goals Report 2020. United Nation; 2020. 6. International Planned Parenthood Federation IPPF. Sustainable Development Goals and Family Planning 2020. London: IPPF; 2016. 7. Osotimehin B. Family planning as a critical component of sustainable global development. Global Health Action. 2015;8(1):29978. 8. Starbird E, Norton M, Marcus R. Investing in Family Planning: Key to Achieving the Sustainable Development Goals. Global Health: Science and Practice. 2016;4(2):191-210. 9. United Nations UN. Family Planning and the 2030 Agenda for Sustainable Development (Data Booklet): UN; 2019. 10. Holzner B. Two Is Enough. Family Planning in Indonesia under the New Order 1968-1998. SOJOURN: Journal of Social Issues in Southeast Asia. 2005;20(1):100-4. 11. Salim E, Adioetomo SM, Arifin EN, Nizam, Pratama A. Population Dynamics and Sustainable Development. UNFPA Indonesia. Jakarta: UNFPA; 2015. 12. Government of Indonesia Gol. Family Planning 2020 commitment: Government of Indonesia2017 May 5th, 2021. Available from:

https://www.familyplanning2020.org/sites/default/files/Govt_Indonesia_FP2020_Commitment_2017.pdf. 13. Government of Indonesia Gol. Family Planning 2020 commitment update: Government of Indonesia2020 May 5th, 2021. Available from:

https://www.familyplanning2020.org/sites/default/files/Indonesia_Questionnaire_2020.pdf. 14. World Health Organization WHO. State of health inequality: Indonesia. Geneva: World Health Organization; 2017. Available from: https://cdn.who.int/media/docs/default-source/gho-documents/12-dec-final-final-17220state-of-health-inequality-in-indonesia-for-web.pdf?sfvrsn=54ae73ea_2. 15. Aryanty RI, Widyantoro N. Sexual and Reproductive Health Services in Indonesia: An Analysis of Equality, Quality and Accountability2019. Available from: https://dawnnet.org/wp-content/uploads/2021/01/Sexual-andReproductive-Health-Services-in-Indonesia-An-Analysis-of-Equality-Quality-and-Accountability_Discussionpaper16.pdf. 16. Ahmed S, Li Q, Liu L, Tsui AO. Maternal deaths averted by contraceptive use: an analysis of 172 countries. Lancet. 2012;380(9837):111-25. 17. Utomo B, Sucahya PK, Romadlona NA, Robertson AS, Aryanty RI, Magnani RJ. The impact of family planning on maternal mortality in Indonesia: what future contribution can be expected? Population Health Metrics. 2021;19(1):2. 18. Mahmud A, Ekoriano M, Titisari A, Wijayanti U, Sitorus M, Rahmadhony A. Determinants Of Modern Contraceptives Use In Indonesia: A Spatial Analysis. Systematic Reviews in Pharmacy. 2021;12:769-77. 19. Nurdin H, Masni, Russeng SS. Determinants contraceptive use after labor in Parepare (comparison between health and health Cempae Lompoe). Enfermeria Clinica. 2020;30(Supplement 4):298-302. 20. Magnani RJ, Nuryana D, Hutchinson P, Aryanty RI, Besral, Utomo B. Determinants of and trends in contraceptive method choice Indonesia. In: Faculty of Public Health Uol, editor. Studies in Family Planning2020. 21. Kistiana S, Gayatri M, Sari D. Determinants of Modern Contraceptive Use among Young Married Women (Age 15-24) in Indonesia. Global journal of health science. 2020;12:37-48. 22. Gafar A, Suza DE, Efendi F, Has EMMa, Pramono AP, Susanti IA. Determinants of contraceptive use among married women in Indonesia. F1000Research. 2020;9:193-. 23. Suantari D, Besral. Determinants of Intrauterine Device Use in Indonesia: Analysis of the Indonesia Demographic and Health Survey for 2002-2012. Journal of International Dental \& Medical Research. 2019;12(1):344-7. 24. Gayatri M, Utomo B. Contraceptive method use in Indonesia: Trends and Determinants between 2007, 2012 and 2017. Indian Journal of Public Health Research \& Development. 2019;10(12):1818-23. 25. Ngome E, Odimegwu C. The social context of adolescent women's use of modern contraceptives in Zimbabwe: a multilevel analysis. United Kingdom, Europe: BioMed 
Central Ltd.; 2014. 26. Stephenson R, Baschieri A, Clements S, Hennink M, Madise N. Contextual influences on modern contraceptive use in sub-Saharan Africa. American journal of public health. 2007;97(7):123340. 27. Ahinkorah BO, Seidu A-A, Appiah F, Budu E, Adu C, Aderoju YBG, et al. Individual and communitylevel factors associated with modern contraceptive use among adolescent girls and young women in Mali: a mixed effects multilevel analysis of the 2018 Mali demographic and health survey. Contraception and Reproductive Medicine. 2020(1). 28. Solanke BL, Oyinlola FF, Oyeleye OJ, llesanmi BB. Maternal and community factors associated with unmet contraceptive need among childbearing women in Northern Nigeria. Contraception and Reproductive Medicine. 2019(1). 29. Zimmerman L. PMA2020: A New Approach to Family Planning Measurement. International Journal of Epidemiology. 2015;44:i33-i. 30. PMA2020. PMA2016/Indonesia Family Planning Brief : KEY FAMILY PLANNING INDICATORS. PMA2020; 2017. 31. Arends-Kuenning M, Kessy FL. The impact of demand factors, quality of care and access to facilities on contraceptive use in Tanzania. Journal of Biosocial Science. 2007;39(1):1-26. 32. Hong R, Montana L, Mishra V. Family planning services quality as a determinant of use of IUD in Egypt. BMC Health Services Research. 2006;6:79-8. 33. RamaRao S, Lacuesta M, Costello M, Pangolibay B, Jones H. The Link Between Quality of Care and Contraceptive Use. International Family Planning Perspectives. 2003;29(2):76. 34. Seiff A. Indonesia to revive national family planning programme. Lancet. 2014;383(9918):683-. 35. Donabedian A. The quality of care. How can it be assessed? Jama. 1988;260 12:1743-8.

\section{Figures}

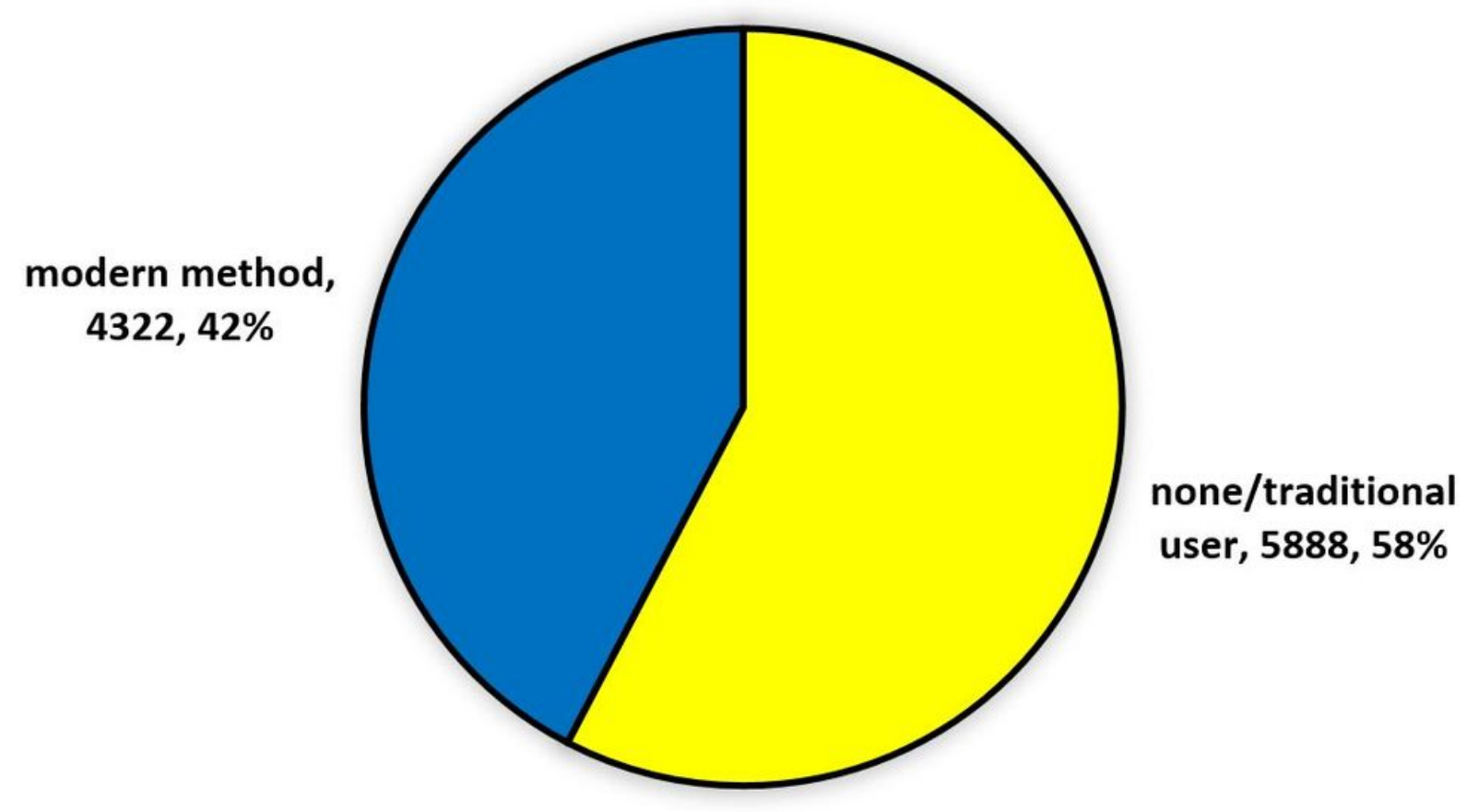


Figure 1

Contraceptive use in 2016 PMA2020 Indonesia survey.

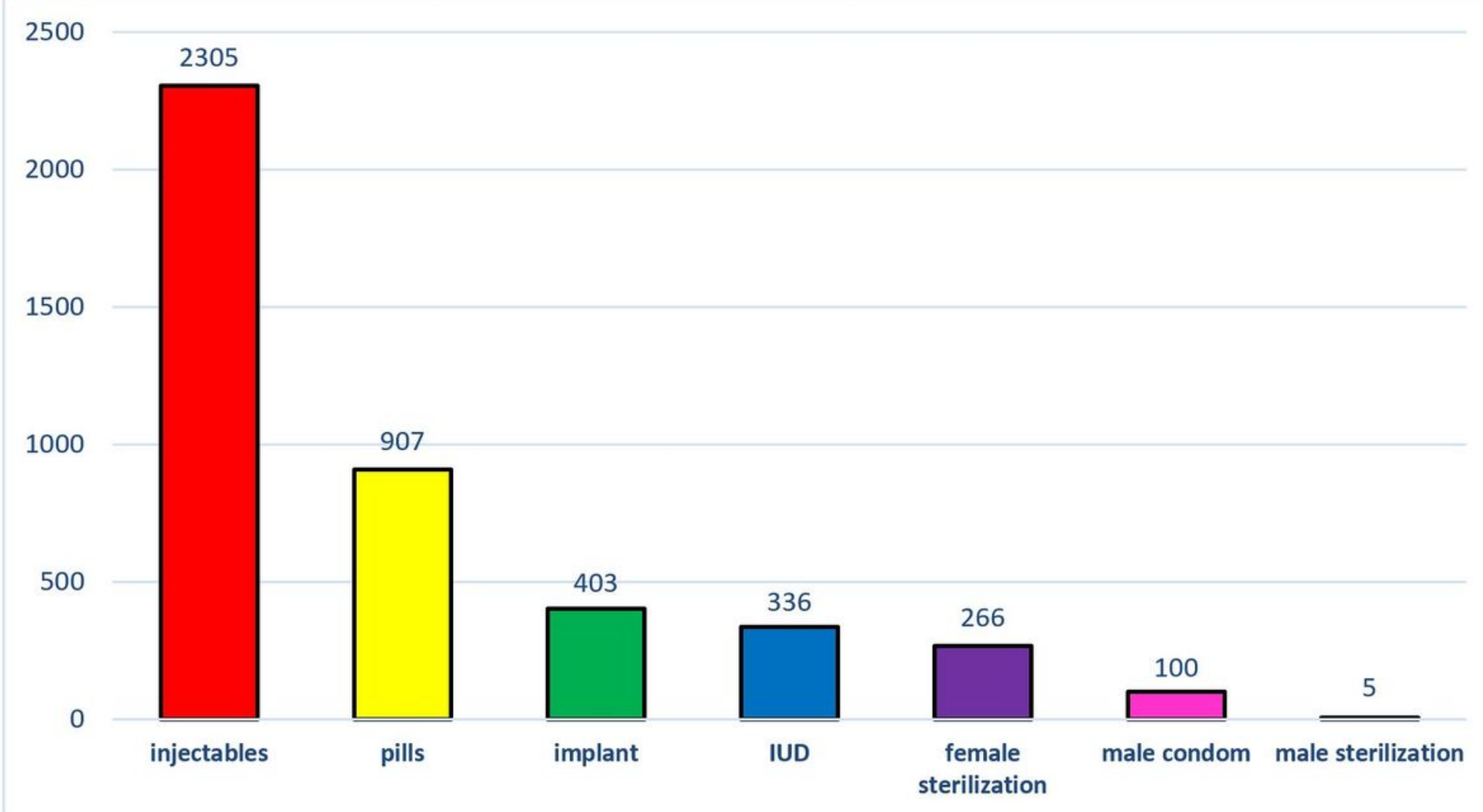

Figure 2

Modern contraceptive prevalence in 2016 PMA2020 Indonesia survey

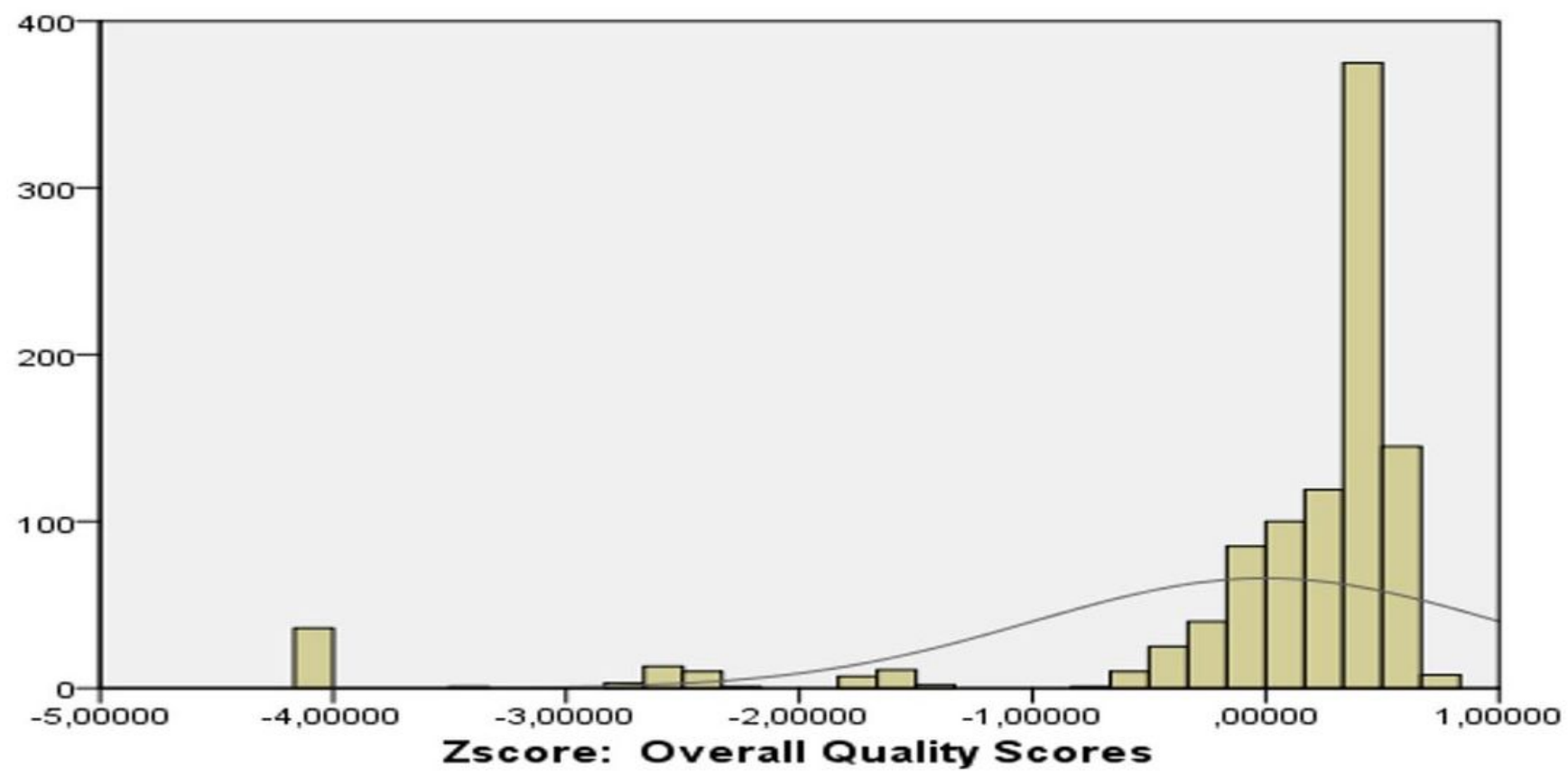

Figure 3 
Normalized Scores for Quality of Care (QoC) index

\section{Supplementary Files}

This is a list of supplementary files associated with this preprint. Click to download.

- CATEGORICALPCAANALYSISFORQUALITYOFCARE.pdf

- QualityofcareandmoderncontraceptiveuseinIndonesia.smcl 